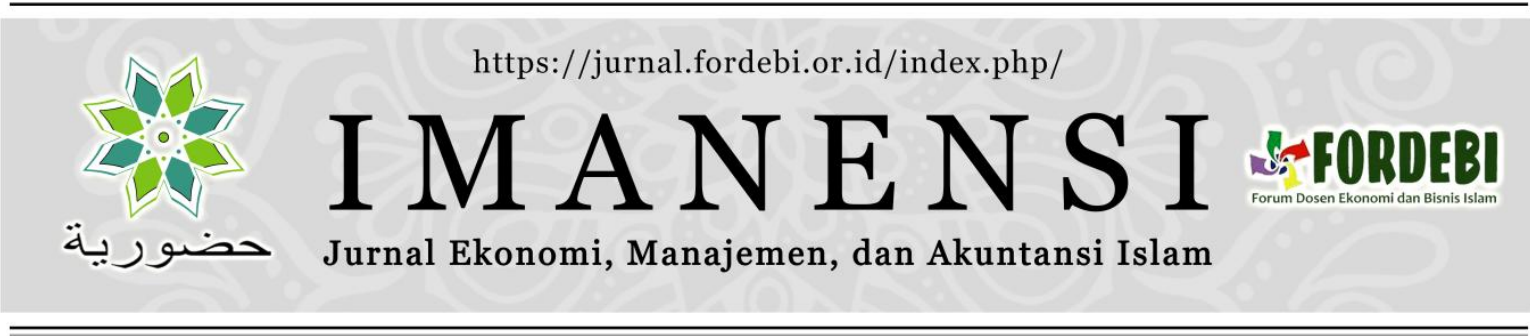

\title{
MENGUNGKAP MOTIVASI SULTAN HAMENGKU BUWONO IX MEMBANGUN SELOKAN MATARAM
}

\author{
Yuana Tri Utomo a,1* \\ a STEI Hamfara, Kenalan Bangunjiwo Kasihan Bantul DIY 55184 Indonesia \\ 1yuanatriutomo@gmail.com* \\ *Corresponding author
}

\section{INFO ARTIKEL \\ IMANENSI \\ Volume 6 \\ Nomor 2 \\ Halaman 65-76 \\ Malang, September 2021 \\ ISSN: 2339-1847 \\ e-ISSN: 2683-9968 \\ Kronologi Artikel: \\ Tanggal Masuk: \\ 10 Mei 2021 \\ Tanggal Revisi: \\ 19 Agustus 2021 \\ Tanggal Diterima: \\ 24 Agustus 2021 \\ Kata Kunci:

\begin{abstract}
Abstrak: Mengungkap Motivasi Sultan Hamengku Buwono IX Membangun Selokan Mataram. Tujuan penelitian untuk mengetahui motivasi Sultan Hamengku Buwono IX membangun Selokan Mataram. Metode penelitian yang digunakan bersifat kualitatif dengan sumber data dari beberapa artikel dan literatur. Data dianalisis dengan pendekatan sejarah menggunakan metode interpretasi. Hasil penelitian menunjukkan bahwa ada tiga motivasi Sultan HB IX, yaitu kebijakan filosofis, ekonomis, dan nasionalisme. Motivasi filosofisnya adalah berasal dari ajaran Sunan Kalijaga bahwa kasultanan Yogyakarta bisa makmur jika dua sungai yang mengapit Yogyakarta dipertemukan dalam satu aliran. Motivasi ekonominya berhubungan dengan cara pandang penguasa dalam menyejahterakan petani untuk irigasi sawah. Pembangunan Selokan Mataram merupakan cermin nasionalisme Sultan dalam membela rakyat dari tuntutan Rhomusa Jepang.
\end{abstract}

Kebijakan ekonomi;

Kasultanan Yogyakarta;

Nasionalisme;

Pembangunan.

\section{Keywords:}

Development;

Economic policy:

Nationalism;

Yogyakarta Sultanate.

\begin{abstract}
Revealing the Motivation of Sultan Hamengku Buwono IX to Build the Mataram Ditch. The purpose of the study was to determine the motivation of Sultan Hamengku Buwono IX to build the Mataram Sewer. The research method used is qualitative with data sources from several articles and literature. Data were analyzed by historical approach using interpretation method. The results showed that the three motivations of Sultan HB IX, namely philosophical policy, economics, and nationalism. The philosophical motivation is derived from the teachings of Sunan Kalijaga that the Sultanate of Yogyakarta can prosper if the two rivers flanking Yogyakarta are brought together in one stream. The economic motivation is related to the perspective of the authorities in the welfare of farmers for irrigating rice fields. The construction of the Mataram Sewer is a reflection of the Sultan's nationalism in defending the people from the demands of the Japanese Rhomusa.
\end{abstract}

Disitasi sebagai: Utomo, YT. (2021). Mengungkap Motivasi Sultan Hamengku Buwono IX Membangun Selokan Mataram. IMANENSI: Jurnal Ekonomi, Manajemen, dan Akuntansi Islam, 6(2), 65-76. https://doi.org/10.34202/imanensi.6.2.2021.65-76.

\section{PENDAHULUAN}

Studi tentang Sultan Hamengku Buwono ke-IX (selanjutnya ditulis Sultan HB IX) sudah banyak dipublikasikan dalam bentuk buku maupun karya ilmiah yang lain. Karya-karya yang sudah dipublikasikan terkait Sultan HB IX biasanya membahas posisi strategisnya di masa transisi sekitar kemerdekaan Indonesia. Interaksi antara Yogyakarta sebagai kasultanan yang kemudian bergabung dengan 
Indonesia menjadi Daerah Istimewa setingkat provinsi dengan kepala daerah seorang gubernur. Buku fenomenal berjudul: Takhta untuk rakyat: celah-celah kehidupan Sultan Hamengku Buwono IX (Roem, 2011) menjelaskan biografi dan perjuangan Sultan HB IX sangat rinci, dari masa kecil Sultan sampai perjalanan terakhirnya. Iswantoro menjelaskan dalam artikelnya tentang dukungan Sultan HB IX terhadap kemerdekaan Republik Indonesia, seperti pemakaian istana kesultanan untuk kantor pemerintahan RI, Sultan juga membuka kas kesultanan untuk membantu biaya operasional negara yang baru lahir ini, juga pertahanan dalam menghadapi serangan umum 1 Maret 1949 sehingga NKRI dinyatakan masih eksis (Iswantoro, 2020). Sultan HB IX selain sebagai raja yang berkuasa di Yogyakarta sekaligus merangkap menjadi gubernur kepala daerah di bawah pemerintahan pusat di Jakarta. Tulisan tentang Sultan HB IX lebih banyak membahas dimensi politik, sosial budaya, dan psikologi sebagai figur kharisma seorang negarawan sejati (Wirawan, 2012). Kepribadian yang unik dan kuat, pada saat menjabat sebagai raja sekaligus sebagai sultan satu sisi dan di sisi yang lain sebagai pejabat publik di NKRI.

Penulis belum menemukan karya ilmiah yang membahas Sultan HB IX terkait dengan pemikirannya tentang ekonomi. Padahal latar belakang pendidikan Sultan HB IX di Universitas Leiden Belanda adalah Indologi, yaitu studi tentang hukum dan ekonomi (Cipta, 2020). Tesis di UIN Sunan Kalijaga berjudul Kebijakan Ekonomi Sultan Hamengku Buwono IX pada awal Orde Baru tahun 1966-1973 masih tersimpan di rak perpustakaan dan belum dipublikasikan. Tulisan yang membahas kebijakan ekonomi Sultan HB IX yang ada adalah tulisan kebijakan ekonomi Sultan HB IX tetapi ketika dia bukan sebagai pemegang otoritas puncak, sementara tulisan ini adalah kebijakan Sultan HB IX dalam pembangunan Selokan Mataram, artinya Sultan HB IX sebagai pemegang otoritas puncak tidak sedang mendapat tugas dari atasannya. Tulisan ini membahas kebijakan Sultan HB IX dalam Pembangunan Selokan Mataram dengan pendekatan sejarah ekonomi.

Obyek tulisan ini adalah pembangunan Selokan Mataram sebagai kebijakan ekonomi Sultan HB IX. Peneliti berharap mampu menemukan motif Sultan HB IX dalam mengambil kebijakan membangun Selokan Mataram. Selokan Mataram dibangun Sultan HB IX pada awal-awal naik takhta sebelum Indonesia merdeka, tepatnya pada tahun 1942. Pada saat itu sedang terjadi transisi (Raditya, 2016). Sultan HB IX memiliki otoritas kekuasaan yang penuh di Yogyakarta. Sebagai Raja sekaligus penguasa tunggal yang jauh dari intervensi pihak luar. Pada saat itu pengaruh pemerintah Hindia Belanda semakin melemah sejak kalah perang di Eropa menghadapi Nazi. Sementara Jepang belum lama masuk ke Jawa menggantikan Belanda. Dengan strategi menganggap saudara tua karena sama-sama dari timur, Jepang bahkan memberikan kepercayaan mutlak kepada Sultan HB IX untuk mengelola Yogyakarta. Apalagi pada saat itu Indonesia belum merdeka, sehingga Sultan HB IX tidak berada pada posisi yang dipimpin oleh presiden Soekarno. Dengan alasan itulah, obyek pembangunan Selokan Mataram dijadikan fokus dalam penelitian ini. Kebijakan Sultan HB IX dalam pembangunan Selokan Mataram ini dielaborasi sedemikian rupa untuk mengungkap motivasi Sultan HB IX membangun Selokan Mataram.

\section{METODE}

Penelitian ini termasuk studi tokoh dalam kerangka kualitatif dan terkategori sebagai penelitian pustaka (Furchan, 2005). Sumber data didapat dari artikel-artikel yang sudah terpublikasi di beberapa jurnal ilmiah, literatur-literatur yang ada di perpustakaan Yogyakarta, dari dokumen arsip-arsip pemerintahan DIY khususnya 
periode Sultan HB IX, dan dari wawancara kepada beberapa tokoh budayawan yang mengetahui betul Sultan HB IX dengan Selokan Mataram sebagai obyek penelitian. Tulisan ini menggunakan pendekatan historis, filosofis, dan dianalisis dengan metode interpretasi. Pendekatan historis karena mengkaji sejarah yang terkait dengan kebijakan ekonomi dan pendekatan filosofis karena mengungkap motivasi yang ada pada Sultan HB IX ketika mengeluarkan kebijakan pembangunan Selokan Mataram (Connolly, 2016).

Interpretasi dilakukan oleh peneliti untuk menafsirkan fakta peristiwa sejarah yang terjadi dengan mengedepankan obyektifitas agar penelitiannya tidak menjadi bias (Abdurrahman, 2011). Berdasarkan hasil wawancara dengan KMT Drs. H. Condro Purnomo pada tanggal 20 September 2019 jam 13.30 di Masjid Pathok Negoro Dongkelan Yogyakarta menjelaskan bahwa tokoh-tokoh yang terlibat dengan pembangunan Selokan Mataram ini sekarang sudah banyak yang meninggal dunia. Atas dasar itu pelacakan terhadap sumber-sumber primer melalui wawancara menjadi terkendala sehingga hasil penelitian ini menjadi sangat terbatas.

\section{HASIL DAN PEMBAHASAN}

\subsection{Biografi dan Lingkungan Sosial Sultan HB IX}

Sumber biografi Sultan HB IX diambil dari dua buku yang otoritatif, Takhta untuk rakyat: celah-celah kehidupan Sultan Hamengku Buwono IX (Roem, 2011) dan Raja di Negara Republik (Monfries, 2018). Dua buku ini menjelaskan kehidupan Sultan HB IX dari masa kecil sampai masa tuanya. Buku pertama ditulis oleh orang Indonesia yang dekat dengan Sultan HB IX, ditulis ketika dia masih hidup sehingga penulis dalam menggali datanya dengan metode wawancara langsung dengan sumber primer. Buku kedua ditulis di Australian National University (ANU), diberi sambutan oleh Gubernur DIY Sultan HB X dengan metode pengumpulan data lebih modern seiring dengan waktu terbitnya pada tahun 2018. Dua buku di atas memiliki ketebalan hampir 500 halaman.

Hamengku Buwono IX lahir di Yogyakarta pada tanggal 12 April $1912 \mathrm{M}$ dari rahim seorang ibu bernama Raden Ayu Kustilah dan ayahnya bernama Pangeran Haryo Puruboyo (Sultan Hamengku Buwono ke-VIII). Nama kecil HB IX adalah Dorodjatun dan di lingkungan keraton dikenal secara resmi sebagi Gusti Raden Mas Dorodjatun. Hari kelahirannya pada Jum'at Malam, sekitar jam 22.30 di kediaman ayahanda di Kampung Sompilan, Jl. Ngasem 13 Yogyakarta, sekarang lebih dikenal dengan Pakuningratan. Sejak lahir sampai umur sekitar empat tahun, Dorodjatun hidup bersama-sama dengan saudara-saudara seayah lain ibu dalam suasana keluarga keraton Yogyakarta yang rukun dan damai (Purwanto, 2018). Dorodjatun hidup terpisah dengan sang ibu sejak pengangkatan ayahnya menjadi putra mahkota karena pulang ke rumah Kakeknya, KGPA Mangkubumi.

Dorodjatun kemudian in de kost di keluarga Belanda bernama Mulder, seorang kepala sekolah pada NHJJS (Neutrale Hollands Javaanse Jongens School) bersama dengan beberapa pangeran yang lain di rumah yang berbeda-beda. Dorodjatun mendapatkan pendidikan di keluarga Mulder seperti pendidikan orangorang pada umumnya, tanpa ada abdi dalem yang melayani kebutuhan sehariharinya. Sejak saat itu, Dorodjatun menjadi keluarga Mulder dengan panggilan Henkie. Sehari-hari berkomunikasi dengan bahasa Belanda sebagai bahasa pengantar, meskipun terkadang menggunakan bahasa Jawa sebagai bahasa ibu. Memasuki masa sekolah, Henkie dimasukkan ke sekolah Frobel (sekarang semacam Taman Kanak-Kanak) di Bintaran Kidul kemudian melanjutkan ke sekolah dasar Eerste europese Lagere School B yang dalam bahasa Jawa dikenal dengan sekolah Kidul Ngloji. Hobinya memasak, sepak bola dan terlibat dalam klub kepanduan NIPV 
(Ned. Indische Padvinders Club). Tamat dari sekolah dasar, Henkie melanjutkan studinya ke tingkat menengah di HBS (Hoogere Burger School) Semarang sampai ada keputusan dari Ayahnya agar dia melanjutkan studi ke Belanda (Roem, 2011).

Bulan Maret 1930, Henkie berangkat ke Belanda ditemani oleh Pangeran Prabuningrat dan disertai oleh keluarga seorang administrator dari pabrik gula Gesikan. Selama di Belanda, dia tinggal dengan kepala sekolah, Mourik Broekman. Nama sekolahnya Harleem Lyceum tempat belajarnya orang-orang dari Nusantara (Indonesia), dari keluarga pangeran atau keluarga kaya. Diantara mata pelajaran yang dipelajarinya adalah matematika, sejarah, perniagaan, geografi, dan beberapa bahasa Eropa. Pendidikan tingkat menengah di Belanda dia selesaikan selama sembilan tahun karena harus ada penyesuaian-penyesuaian antara pendidikan di Nusantara dengan pendidikan di tempat baru di Belanda. Selama studi di tingkat menengah ini, beberapa kali Henkie pindah sekolah. Selesai di tingkat menengah, Henkie melanjutkan studinya di tingkat universitas. Pada saat itu umurnya sekitar 23-24 tahun. Dia memilih universitas terkemuka dan tertua di Kota Leiden, yaitu universitas Rijksuniversiteit fakultas Indologi gabungan dari bidang hukum dan ekonomi. Disana, Henkie atau Dorodjatun belajar administrasi publik, hukum kolonial, ekonomi dan mata kuliah lain di fakultas Indologi sampai merampungkan tesis doktoralnya pada bulan Desember tahun 1937. Yang menarik, pada saat kuliah di Belanda ini, Dorodjatun bertemu dengan Juliana, yang kelak menjadi ratu Belanda. Dia juga bertemu dengan Menteri Kolonial Belanda untuk Hindia Belanda, Welter, Gubernur Jenderal de Jonge dan pejabat senior kolonial, Meyer Ranneft (Monfries, 2018).

Selesai studi di Belanda, pada Oktober 1939 Dorodjatun kembali ke tanah air, dijemput langsung oleh Sultan HB VIII di Tanjung Priok-Betawi kemudian menginap tiga hari di Hotel Des Indes bersama rombongan keraton sebelum bertolak ke Yogya. Rombongan Dorodjatun pulang ke Yogja naik keretaapi dan pada saat itu HB VIII sedang sakit keras. Sampai pada saatnya, tanggal 22 Oktober 1939 HB VIII wafat. Seiring dengan itu, dinamika suksesi dilanjutkan oleh Dorodjatun sebagai Sultan Hamengku Buwono IX. Diantara dinamika suksesinya adalah kontrak politik Dorodjatun yang tidak mudah ditundukkan dengan pemerintah Hindia Belanda yang diwakili oleh Gubernur Adam. Dorodjatun resmi naik takhta pada tanggal 18 Maret 1940. Di antara petikan pidatonya adalah sebagai berikut: "Walaupun saya telah mengenyam pendidikan Barat yang sebenarnya, namun pertama-tama saya adalah dan tetap orang Jawa. Maka selamanya tak menghambat kemajuan, adat tetap menduduki tempat yang utama dalam Kraton yang kaya tradisi ini." (Ratmanto, 2012).

Eropa sedang terjadi perang oleh tentara Nazi yang menduduki seluruh wilayah Belanda. Sementara dari Asia, Jepang bergerak menyerbu pelabuhan perang Amerika Serikat di Pearl Harbour. Gubernur Jenderal Belanda, W.L. Tjarda van Starkenborgh mengumumkan perang melawan Jepang pada 6 Desember 1941. Dia berunding dengan Gubernur Yogyakarta, Dr. L. Adam di Jakarta dalam mengantisipasi jika Jepang memasuki wilayah Hindia Belanda. Diantara keputusannya adalah mengajak Sultan HB IX menyingkir ke Australia, meski ditolak mentah-mentah oleh Sri Sultan HB IX. Dan pada 1 Maret 1942, Jepang mendarat di Pulau Jawa, kemudian memaksa Hindia Belanda menyerah tanpa syarat. Jepang memberikan wewenang lebih luas kepada Sultan HB IX untuk mengurus Kasultanan Yogyakarta secara langsung (Roem, 2011).

Pemerintah Jepang memandang wilayah Kasultanan Yogyakarta sebagai wilayah yang sempit dengan tingkat kesejahteraan yang minim, tidak mampu menghasilkan bahan pangan yang dibutuhkan oleh masyarakatnya. Dengan alasan 
itu, Sultan HB IX melakukan diplomasi kepada Jepang agar diberi bantuan keuangan untuk membangun sarana irigasi, yang kemudian lebih dikenal dengan "Selokan Mataram". Kebijakan Sultan HB IX yang lain adalah pemberlakuan otonomi di kabupaten seluruh Daerah Istimewa Yogyakarta sejak akhir masa pendudukan Jepang. Sultan HB IX juga menginisiasi berdirinya JAKTI (Yayasan Kredit Tani) sebagai lembaga untuk membantu petani yang kekurangan modal dalam memajukan usahanya. Eksistensi pabrik gula Madukismo yang masih berdiri sampai sekarang juga tidak bisa dilepaskan dari peran Sultan HB IX ketika masa revolusi mencegah Belanda melakukan bumihangus terhadap pabrik-pabrik yang didirikannya (Purwanta, 2014).

Proklamasi kemerdekaan Republik Indonesia pada 17 Agustus 1945 di Jakarta disambut gembira oleh seluruh masyarakat Indonesia. Sultan HB IX mengirimkan telegram berisi ucapan selamat kepada Ir. Soekarno dan Muh. Hatta sebagai proklamator kemerdekaan RI sekaligus merupakan bentuk pengakuan kedaulatan Negara Kesatuan Republik Indonesia. Yogyakarta sebetulnya bisa merdeka sendiri, karena memiliki sistem pemerintahan lebih dulu dan lebih siap, namun Sultan HB IX tidak mengambil opsi tersebut, melainkan justru bergabung dengan NKRI dan Yogyakarta kemudian menjadi Daerah Istimewa di bawah kekuasaan NKRI (Baskoro, 2011). Pada awal kemerdekaan ini, Yogyakarta sempat menjadi ibu kota revolusi dan Sultan HB IX untuk pertama kalinya menjadi menteri negara pada Kabinet Syahrir III tahun 1946 yang sukses mengantarkan Yogyakarta menjadi Daerah Istimewa dengan berbagai reformasi lokal sebagai percontohan untuk daerah-daerah lainnya. Reformasi lokal itu diantaranya adalah penggunaan Bahasa Indonesia sebagai bahasa resmi (bukan bahasa Jawa), menata struktur pemerintahan dari pusat sampai desa, memulai serangkaian proyek ekonomi, pendidikan, dan lain-lain. Ratmanto menjelaskan transisi pemerintahan Republik Indonesia di Yogyakarta dengan Sultan Hamengku Buwono IX sebagai figur sentral yang memiliki kharisma sangat agung (Ratmanto, 2012).

Selama masa pemerintahan Soekarno dari tahun 1945 sampai dengan tahun 1967, Sultan HB IX menjabat sebagai Menteri Negara urusan Daerah Istimewa, menjadi Koordinator Keamanan Internal dan Menteri Pertahanan. Dia juga pernah menggantikan Urip Sumoharjo sebagai Gubernur Militer yang berhasil mengkombinasikan kekuatan sipil dan militer di setiap daerah. Reputasinya semakin kuat sebagai Nasionalis yang anti penjajahan kolonial, kepatuhannya kepada pemerintah pusat di Jakarta tidak diragukan, kemampuannya membentuk laskar rakyat sebagai cikal bakal Tentara Nasional Indonesia bersama Urip Sumoharjo. Yogyakarta pernah menjadi pusat ibu kota, kemenangan perang melawan Belanda dalam serangan umum 1 Maret bersama Suharto, sampai pada suatu titik Sultan HB IX mengundurkan diri di era demokrasi terpimpin Soekarno Tahun 1953. Pada November 1963, Soekarno mengangkat HB IX kembali untuk menjabat di BPK (Badan Pemeriksa Keuangan) sampai masa pergantian kekuasaan kepada Suharto di era Orde Baru (Roem, 2011).

Sultan HB IX di masa orde baru menjadi Perdana Menteri untuk bidang Ekonomi, Keuangan dan Pembangunan. Sultan selaku pejabat publik berpidato menyampaikan beberapa kebijakan terkait stabilitas ekonomi Negara. Seruan agar kalangan elite berperilaku hidup sederhana demi kelangsungan pembangunan. Sultan HB IX juga mengkonsolidasikan berbagai hubungan ekonomi dengan luar negeri, seperti bergabung dengan IMF pada Agustus 1966, Bank Dunia, dan ADB (Asian Development Bank), serta menyetujui Undang-Undang terkait investasi asing. Pada tahun 1968, Sultan HB IX diangkat menjadi Koordinator Menteri Bidang Ekuin (Ekonomi, Keuangan dan Industri) pada kabinet pembangunan yang pertama. 
Sultan HB IX juga pernah menjabat wakil presiden yang kosong sejak pengunduran diri Muh. Hatta tahun 1956. Jabatan wakil presiden ini diemban dari tahun 1972 sampai tahun 1977 dengan kondisi kesehatan yang menurun. Sultan HB IX menyerahkan takhtanya untuk rakyat seiring dengan usianya yang semakin sepuh dan sampai pada akhirnya Sultan HB IX meninggal pada tahun 1988 (Monfries, 2018).

\subsection{Kebijakan Pembangunan Ekonomi}

Kebijakan ekonomi adalah prinsip yang diambil oleh pengambil kebijakan dalam hal ini adalah negara sebagai keputusan untuk mengarahkan kegiatan pembangunan di bidang ekonomi. Kebijakan ekonomi termasuk jenis kebijakan substantif, bukan jenis kebijakan kelembagaan (Suharno, 2016). Keterlibatan negara dalam kebijakan ekonomi di masa peralihan dari penjajah Jepang menuju era kemerdekaan menunjukkan bahwa perekonomian di awal-awal era kemerdekaan ini dipengaruhi oleh pemikiran John Maynard Key, ekonom asal Inggris. Kebijakan yang paling menonjol adalah tuntutan agar negara turut campur dalam perekonomian untuk menyelamatkan kegagalan swasta dalam sektor perekonomian (Keynes, 2017). Sultan HB IX selaku kepala negara pada waktu itu, ketika melakukan keputusan untuk membangun Selokan Mataram mengandung arti bahwa kebijakan itu adalah kebijakan negara.

Kebijakan ekonomi diambil pemerintah dalam rangka memberikan jalan keluar problem perekonomian yang terjadi di tengah-tengah masyarakat agar tujuan pembangunan untuk mensejahterakan rakyat tercapai. Dalam melakukan campur tangan perekonomian, negara tidak selalu berhasil dikarenakan beberapa faktor diantaranya adalah keterbatasan informasi. Negara yang gagal dalam kebijakan ekonominya bisa berdampak pada tidak terpenuhinya kebutuhan dasar (al-hajah alasasiyyah) masyarakat (Al-Maliki, 2009). Oleh karena itu, pembangunan ekonomi diharapkan bisa mengurangi ketimpangan distribusi kekayaan yang ada sehingga tidak terjadi kelangkaan sarana pemuas kebutuhan sehari-hari di masyarakat. Kebijakan pemerintah dalam sektor ekonomi ditujukan untuk memenuhi rasa keadilan pada masyarakat.

Kebijakan ekonomi di negara manapun diarahkan pada perhatian terhadap sumber-sumber primer ekonomi, yaitu: pertanian, perindustrian, perdagangan dan tenaga kerja manusia (Al-Maliki, 2009). Fokus kajian artikel ini adalah kebijakan Sultan HB IX terkait dengan pembangunan Selokan Mataram. Sehingga sumber ekonomi yang menjadi perhatian dalam tulisan ini adalah sumber ekonomi yang pertama, yaitu pertanian, bukan perindustrian, bukan perdagangan bukan pula tenaga kerja manusia kecuali yang ada kaitannya dalam beberapa hal saja. Meskipun kondisi Yogyakarta pada saat itu sedang terjadi perang sebagaimana di Indonesia sebelum merdeka pada umumnya, konsentrasi pemerintah dalam hal ini Hindia Belanda untuk melakukan pembangunan sedikit banyak terganggu, pembangunan dalam arti peningkatan taraf hidup tidak berjalan, tetapi aktifitas ekonomi masyarakat tetap berjalan karena merupakan dloruriyat bagi masyarakat tersebut, artinya jika aktivitas ekonominya berhenti maka masyarakat bisa mati atau bubar. Sumber ekonomi yang empat di atas menjadi tulang punggung aktivitas ekonomi masyarakat sebagai perkara yang primer, berbeda dengan sumber ekonomi yang lain, seperti: pariwisata, upah (termasuk pajak bagi negara), sarana transportasi dan sebagainya.

Kebijakan pemerintah tidak begitu signifikan karena keamanan masyarakat sedang terganggu, tingkat pendidikan masyarakat rendah, dan kesehatan menjadi sangat mahal. Keamanan, pendidikan dan kesehatan ini seharusnya menjadi 
konsentrasi pemerintah dalam kebijakan ekonominya karena merupakan dloruriyat publik dan bersifat makro (Ika Yunia Fauzia, 2014). Namun kebutuhan primer lainnya, seperti sandang, pangan dan papan bisa tetap didapatkan meskipun serba terbatas dengan mengandalkan perputaran ekonomi mikro di pasar-pasar tradisional. Pembangunan pada masa itu banyak dilakukan oleh pemerintah Belanda dengan kebijakan-kebijakan ekonomi yang menguntungkan mereka dan menyengsarakan masyarakat. Misalnya kebijakan tanam paksa (cultur stelsel) pada tahun 1830 sampai 1870 di sektor pertanian memaksa masyarakat menanam komoditi dengan orientasi pasar ekspor di Eropa yang tidak dibutuhkan oleh petani, seperti; tebu, karet, kopi, nila, dan sejenisnya. Kebijakan tanam paksa ini berimplikasi pada diabaikannya industri kecil, padahal industri kecil rumah tangga menjadi poros perputaran ekonomi masyarakat pribumi pada waktu itu. Masyarakat diwajibkan dan dipaksa bekerja di perkebunan-perkebunan Belanda selama 75 hari dalam setahun dan meninggalkan industri rumah tangga mereka. Kebijakankebijakan ekonomi era kolonial Belanda mengakibatkan dualisme ekonomi, antara ekonomi tradisional dan ekonomi modern (R.Z. Leirissa, 2012).

Kebijakan pemerintah kolonial Belanda pasca politik etis merubah pandangan mereka terhadap sektor industri kecil rumah tangga. Pada awalnya perhatian hanya terfokus pada industri ekspor oleh industri mereka saja kemudian bergeser mereka melakukan perhatian juga terhadap industri kecil milik masyarakat. Pada tahun 1927, pemerintah kolonial Belanda melakukan pembinaan para perajin perak di Kota Gede mengenalkan teknik baru dalam pembakaran. Pada tahun itu juga diadakan pameran produk kerajinan dari industri-industri yang ada di pedalaman atau pedesaan wilayah Kerajaan Mataram dengan tujuan mengangkat ekonomi masyarakat desa dari hasil penjualan produk-produk yang dipamerkan. Perhatian pemerintah kolonial Belanda terhadap industri kecil pasca politik etis ini belum bisa memperbaiki kondisi perekonomian masyarakat secara signifikan karena adanya unsur persaingan dengan pengusaha-pengusaha-pengusaha Tionghoa. Disamping itu juga pemerataan pembangunan yang berkurang.

Lebih jauh, kebijakan ekonomi kolonial Belanda dengan dukungan kekuatan militer menyebabkan terjadinya kesenjangan dan ketimpangan division of labor di masyarakat Indonesia sampai tahun 1945. Tenaga masyarakat pada waktu itu dimanfaatkan hanya untuk kuli kontrak, buruh kasar, kaum jongos, dan semisalnya. Sementara di sisi lain, ada kalangan elit sebagai upper class mengontrol dan menguasai asset-aset produksi srategis yang notabene mereka adalah pendatang berkewarganegaraan asing. Tanah dan pertanian pribumi tersedot oleh kerakusan penjajah Hindia Belanda hanya demi memenuhi pasar perdagangan dunia (Hempri Suyatna, 2017).

\subsection{Pembangunan Selokan Mataram}

Latar belakang pendidikan Sultan HB IX di Leiden Belanda adalah Indologi, yaitu gabungan antara studi hukum dan studi ekonomi. Meskipun sekian lama tinggal di Belanda, Sultan HB IX tetap merasa dirinya adalah orang Jawa yang bisa menjaga kepribadiannya. Pada saat Sultan HB IX dilantik menjadi Raja Yogyakarta, wilayah Yogya terdiri dari lima kabupaten dan satu kota dengan luas 3.168 kilometer persegi dibanding dengan wilayah Jawa 132.187 kilometer persegi secara keseluruhan. Penduduk Yogyakarta pada saat itu diperkirakan sebanyak 1.178.051 jiwa orang pribumi dengan tambahan beberapa ratus jiwa (tidak sampai menyentuh angka ribuan) populasi bangsa lain. Pada saat penjajah Jepang hadir menggantikan Belanda, Jepang hendak memperkuat posisi pendudukannya dengan mengambil hati rakyat. Pada awal kedatangannya, Jepang diterima oleh Rakyat dengan gembira 
seakan menjadi juru selamat dari penjajahan Belanda. Kemudian Jepang melakukan program pendudukan melalui proyek-proyek pembangunan yang membutuhkan banyak tenaga kerja. Rakyat diharapkan bisa membantu mereka untuk perang di Asia Timur Raya. Beberapa kebijakan Jepang di bidang politik misalnya dengan membentuk tentara PETA, di bidang pendidikan dengan menghilangkan diskriminasi antara kaum pribumi dengan warga asing warisan politik etis Belanda, dan di bidang ekonomi dengan pengawasan ekonomi secara ketat dan merekrut pemuda-pemuda dalam negeri untuk kerja paksa yang lebih dikenal dengan Romusa.

Romusa adalah program Jepang dalam memaksa rakyat agar mau bekerja sebagai buruh atau pekerja kasar lainnya di proyek-proyek militer mereka (Apid, 2008). Sultan HB IX berhasil meminimalisir penderitaan rakyat dengan siasat mengelabui Jepang dengan menyembunyikan angka-angka statistik terkait perekonomian Yogyakarta yang sebenarnya. Jepang menganggap Yogyakarta sebagai daerah yang sempit dengan tingkat ekonomi minus dan mengalami kekeringan sehingga tidak mampu menyumbang hasil bumi untuk tentara pendudukan Jepang. Secara ekonomi memang pada saat itu wilayah Yogyakarta termasuk wilayah yang relatif miskin ditambah dengan kondisi ekonomi dunia yang sedang depresi tahun 1930-an.

Sebuah proyek pekerjaan umum di masa Jepang ini adalah pembangunan Selokan Mataram dengan propaganda sebagai proyek penyediaan air terbesar di Jawa. Penyediaan air di masa Belanda ditujukan kepada perusahaan-perusahaan Belanda sementara proyek Selokan Mataram ini ditujukan untuk mencukupi kebutuhan air rakyat. Dalam rangka menyukseskan proyek ini, Sultan HB IX bahkan berdiplomasi agar Jepang mau membantu rakyat Yogyakarta dengan keuangan untuk membangun sarana irigasi pertanian, yang kemudian diwujudkan menjadi selokan Mataram (Tino, 2010). Proyek ini menjadi motivasi Sultan HB IX dalam sektor ekonomi untuk menyejahterakan masyarakat Yogyakarta pada awal pemerintahannya. Pembangunan saluran ini menjadi pintu air yang terbuka dan tertutup sebagai penadah hujan di daerah tergenang mengalir ke laut, terutama di selatan daerah Adikarto, selain itu juga sebagai sumber aliran air dari kali progo ke daerah timur yang kering karena kekurangan air seperti di daerah Sleman (Roem, 2011).

Selokan mataram adalah saluran irigasi sepanjang $31.2 \mathrm{~km}$ itu menghubungkan Kali Progo di sebelah barat dan Kali Opak di sebelah timur. Pada awalnya merupakan sebuah parit yang ada sejak tahun 1914 di masa penjajahan Belanda. Saat itu, sistem pengairan di Yogyakarta masih tergolong tradisional dengan tadah hujan. Seiring dengan kebutuhan warga Yogyakarta pada air untuk persawahan dan perkebunan tebu semakin meningkat, maka pada tahun 1942 sampai tahun 1945 dibangunlah Selokan Mataram atau dalam bahasa Jepang dikenal dengan Kanal Yoshiro. Pembangunan selokan Mataram ini dilakukan oleh warga masyarakat Yogyakarta sendiri pada saat Jepang menggalakkan Romusha sebagai program kerja paksa untuk mengeksploitasi kekayaan alam Indonesia demi kepentingan perang Jepang. Dengan demikian, tidak ada warga masyarakat Yogyakarta yang dipaksa kerja oleh Jepang sebagai Romusha dan bekerja keluar wilayah atau bahkan keluar negeri, melainkan kerja untuk pembangunan Yogyakarta sendiri dengan menggali parit untuk selokan Mataram. Sultan HB IX tidak rela melihat rakyatnya menderita akibat romusha dan bahkan jauh dari sanak keluarganya. 
Inisiasi Sultan HB IX untuk membangun Selokan Mataram ini mendapat dukungan penuh dari warga masyarakat (Clark, 2017). Pada saat itu di masyarakat terdapat cerita semacam ajaran yang tidak tertulis dari Sunan Kalijaga bahwa kemakmuran rakyat Mataram (Yogyakarta) bisa terwujud apabila dua arus sungai yang mengalir mengapit Yogyakarta bersatu. Karena itulah aliran Kali Progo yang mengalir di sisi barat Yogyakarta ditemukan dengan aliran Kali Opak yang di sebelah timur Yogyakarta dalam satu aliran baru yaitu Selokan Mataram ini. Pada akhirnya, Yogyakarta memiliki saluran irigasi yang bisa mengairi persawahan penduduk dan beberapa perkebunan tebu. Ajaran Sunan Kalijaga ini menjadi motivasi filosofis Sultan HB IX membangun Selokan Mataram.

Perkembangan berikutnya, seiring dengan bertambahnya jumlah penduduk, saluran irigasi Selokan Mataram yang semula sulit diakses karena harus melewat perkebunan dan persawahan milik warga, sekarang menjadi daerah yang strategis dan mudah diakses. Ruas jalan di sepanjang Selokan Mataram sangat padat dan ramai dengan volume yang sangat tinggi menyebabkan kemacetan di banyak titik. Misalnya di perempatan jalan Selokan Mataram daerah Gejayan dan daerah perempatan sebelah utara Fakultas Tekhnik UGM. Selokan Mataram yang sekarang berada di wilayah Kabupaten Sleman ini telah ramai oleh rumah-rumah penduduk, toko-toko, bahkan beberapa industri rumah tangga dan pabrik menjadikan fungsi Selokan Mataram bertambah dari sekedar irigasi menjadi drainase bagi penduduk perkotaan.

Saluran irigasi Selokan Mataram ini melewati 16 kali: Petel, Krupuk, Konteng, Mlinting, Sipol, Krasak, Jambu, Krajak, Bedog, Pelem, Batang, Jlegog, Denggung, Winongo, Buntung dan Tolo. Selokan Mataram mengairi 5.200 hektar lahan persawahan, penggelontoran sistem sanitasi, industri gula, dan 85 unit sadap (Kusumawati, 2019). Aktifitas penduduk yang tinggal di sekitar Selokan Mataram menyebabkan dampak positif dan negatif. Dampak negatif yang terjadi adalah ketika penduduk membuang sampah setiap hari di sepanjang aliran Selokan Mataram menyebabkan sampah menumpuk mengakibatkan aliran air jadi terhambat dan mengurangi debit air yang mengalir. Jepang gagal dalam menjalankan kebijakan ekonomi pertanian karena salah sasaran. Situasi perang pada saat itu menjadikan rakyat yang dipaksa mandiri dalam pemenuhan kebutuhan pokok tidak berhasil. Kebijakan ekonomi Jepang dengan strategi pelatihan bagi petani, pengenalan inovasi teknik tanam dan produk beras dari padi unggulan di tolak oleh masyarakat. Peran Sultan HB IX mampu mengecoh Jepang sehingga kebijakan ekonominya tidak berpihak ke Jepang melainkan berpihak masyarakat Yogyakarta yang kemudian bergabung dengan Indonesia. Sampai kemudian kemerdekaan Indonesia diproklamasikan oleh Presiden Soekarno dengan didampingi oleh Mohamad Hatta dan tokoh-tokoh kemerdekaan lainnya.

\section{SIMPULAN}

Kebijakan membuat Selokan Mataram dimotivasi oleh nilai filosofis, ekonomis dan sikap nasionalisme. Ajaran Sunan Kalijaga tentang kemakmuran Yogyakarta hanya bisa dicapai dengan mengalirkan menjadi satu dua sungai yang mengapit Yogyakarta di sebelah barat dan di sebelah timur mendorong Sultan HB IX membangun Selokan Mataram. Adapun motivasi ekonominya, pembangunan Selokan Mataram ini bisa menyelamatkan generasi muda warga Yogyakarta dari perbudakan Romusha Jepang dan bisa menjadi irigasi persawahan penduduk di sekitarnya. Selain itu, Sultan HB IX yang mampu berdiplomasi kepada Jepang agar pembangunan Selokan Mataram didanai oleh Jepang menunjukkan nasionalisme perilaku Sultan HB IX. 
Kajian ini bisa dikembangkan untuk mengetahui jenis sistem ekonomi yang ada di Kasultanan Yogyakarta. Hal ini bisa terjadi karena mengingat peran Sultan HB IX sebagai orang yang mengorganisir dan menjalankan sistem pada masa itu tentu Sultan HB IX terikat dengan kaidah-kaidah atau norma-norma Kasultanan Yogyakarta dimana sistem ekonomi Islam telah berlaku di Kasultanan Yogyakarta.

\section{REFERENSI}

Abdurrahman, D. (2011). Metodologi Penelitian Sejarah Islam. Yogyakarta: Penerbit Ombak.

Al-Maliki, A. (2009). Politik Ekonomi Islam. Bogor: Al Azhar Press.

Apid, H. F. (2008). Romusa: Sejarah Yang Terlupakan. Yogyakarta: Penerbit Ombak. Baskoro, H. (2011). Wasiat HB IX; Yogyakarta Kota Republik. Yogyakarta: Galang Press.

Cipta, S. E. (2020). Menoedjoe Repoeblik Bangsawan Dalam Pusaran Kemerdekaan : The role of K . G . P . A . A . Paku Alam VIII \& Sri Sultan HB IX in defending Indonesia ' $s$ Independence. Journal of Social Science, 29-35.

Clark, D. P. (2017). Stages of diversification in high performing Asian economies. Journal of Economic Studies, 44(6), 1017-1029. https://doi.org/ 10.1108/JES12-2016-0250, 1017-1029.

Connolly, P. (2016). Aneka Pendekatan Studi Agama. Yogyakarta: Ircisod bekerjasama dengan LKiS.

Furchan, A. (2005). Studi Tokoh; Metode Penelitian Mengenai Tokoh. Yogyakarta: Pustaka Pelajar.

Hempri Suyatna, A. S. (2017). Dinamika dan Kebijakan Ekonomi rakyat. Yogyakarta: Taiara Wacana.

Ika Yunia Fauzia, A. K. (2014). Prinsip Dasar Ekonomi Islam; Perspektif Maqashid alSyari'ah. Jakarta: Prenadamedia Group.

Iswantoro. (2020). Peranan Sri Sultan Hamengku Buwono Ix Dalam Menegakkan Kemerdekaan Negara Republik Indonesia. JUSPI (Jurnal Sejarah Peradaban Islam), 158.

Keynes, J. M. (2017). The General Theory of Employment, Interest and Money. Modern Economic Classics-Evaluations Through Time, 108-153.

Kusumawati, P. (2019). Potensi selokan Mataram: ulasan keadaan fisik dan kualitas airnya. Jurnal Pendidikan Geografi, 24(2), 108-118. https:// doi.org/10.17977/um017v24i22019p108, 108-118.

Monfries, J. (2018). Raja di Negara Republik; Kehidupan Sultan Hamengku Buwono IX dari Yogyakarta. Yogyakarta: Penerbit Biography.

Purwanta, A. H. (2014). G. Moedjanto tentang Sukarno, Hatta, Hamengkubu Buwono IX. Yogyakarta: Universitas Sanata Dharma.

Purwanto, B. (2018). Nasionalis Pembaru Tanpa Kegaduhan: Biografi Manusiawi Sultan Hamengku Buwono IX. Sasdaya Gadjah Mada Journal of Humanities, 471-476.

R.Z. Leirissa, G. O. (2012). Sejarah Perekonomian Indonesia. Yogyakarta: Penerbit Ombak.

Raditya, M. H. (2016). Kontestasi Kekuasaan dan Keteladanan Semu di Indonesia. Jurnal Imu Sosial dan Ilmu Politik, 1-15.

Ratmanto, A. (2012). Mengawal Transisi. Yogyakarta: Atap Buku dan Mata Padi Presindo.

Roem, M. D. (2011). Takhta untuk rakyat: Celah-Celah Kehidupan Sultan Hamengku Buwono IX. Jakarta: Gramedia Pustaka Utama.

Suharno. (2016). Dasar-Dasar Kebijakan Publik; Kajian Proses dan Analisis Kebijakan. Yogyakarta: Penerbit Ombak. 
Tino, K. (2010). Hamengku Buwono IX; Dari Serangan Umum 1 Maret sampai Melawan Soeharto. Yogyakarta: Navila Idea.

Wirawan, G. (2012). Kepemimpinan Sultan Hamengku Buwono IX dalam Menghadapi Kolonialisme di Wilayah Yogyakarta Tahun 1942-1949. 
Halaman ini sengaja dikosongkan 